\title{
Analysis of Financial Performance and Environmental Sustainability of Coldwater Inland Fisheries in Sikkim Himalaya
}

\section{Kul Bahadur Chettri}

Department of Economics, Sikkim University, 5th Mile, Gangtok, Sikkim, India

Ruma Kundu ( $\square$ rumakundu76@gmail.com )

Department of Economics, Sikkim University, 5th Mile, Gangtok, Sikkim, India https://orcid.org/00000002-7946-2253

\section{Research}

Keywords: Coldwater fisheries, Trout and Carp, PFCS, Productivity, Profitability, Environmental sustainability

Posted Date: January 13th, 2021

DOI: https://doi.org/10.21203/rs.3.rs-143725/v1

License: (9) (i) This work is licensed under a Creative Commons Attribution 4.0 International License. Read Full License 


\title{
Analysis of financial performance and environmental sustainability of coldwater inland fisheries in Sikkim Himalaya
}

\author{
Kul Bahadur Chettri ${ }^{1} \&$ Ruma Kundu*2 \\ ${ }^{1}$ Department of Economics, Sikkim University, $5^{\text {th }}$ Mile, Gangtok, Sikkim, India \\ Email: kulchettri33@gmail.com; Ph: 9851634832 \\ ${ }^{2}$ Department of Economics, Sikkim University, $5^{\text {th }}$ Mile, Gangtok, Sikkim, India \\ Email: rumakundu76@gmail.com; Ph: 9475176186 \\ * Corresponding author: rumakundu76@gmail.com
}

\begin{abstract}
This paper analyses the financial performances in terms of productivity and profitability indices and environmental sustainability with regards to Maximum Sustainable Yield (MSY) through the application of the Gordon-Schaefer Model for the coldwater Primary Fishermen Cooperative Society (PFCS). For this purpose, data has been collected from the secondary sources for the periods 2013-14 to 2018-19. The panel data analysis was carried out to derived the results using the method of ordinary least squares. The study found that PFCS such as Sribadam, Maneybong-Sopakha and Mangshilla have performed better in financial management but there is a probability of thread of sustainability in the future because in some of the periods their actual yield surpasses the MSY. On the other hand, PFCS like Rimbik, Chujachen and Dalep have not been able to bring their financial performances up to the mark because they were more concerned for sustainability. Excessive extraction of fishes from the water bodies for higher profit motive may lead to less availability for the coming generations. The study suggests that in aquaculture or fish farming, there should maintain an equilibrium between financial benefits and environmental sustainability and the resource should be utilised on a sustainable basis.
\end{abstract}


Keywords: Coldwater fisheries, Trout and Carp, PFCS, Productivity, Profitability, Environmental sustainability.

\section{Introduction}

The Himalayan regions have the largest biological diversity in the world characterised by the presence of coldwater many of which harbor fish and largely support subsistence, ornamental and commercial fisheries [1]. In the Himalayas, the fish diversity comprises a large population of indigenous and exotic, cultivable and non-cultivable fish species having the potential for aquaculture practices, capture fisheries and sport fishing [2-5]. The different fish species such as trout (rainbow and brown trout) and carp (grass carp, common carp, Chinese carp, and some species of Indian carp) are the major cultivable fishes of the coldwater [1].

Sikkim is a mountainous state endowed with numerous coldwater resources in the forms of lakes, streams, perennial springs, rivers, reservoirs, etc. which support both capture and culture fisheries in the upland and lowland regions. Due to the hilly terrain, agriculture and other allied activities are not sufficient for rural livelihood; therefore, fish farming has become an important source of livelihood and earnings for the rural people. To utilise the available water resources fruitfully and to develop capture and culture fishery, people have taken the initiative to make fish farming their subsidiary occupation and feel the urge to develop local water resources on a sustainable basis fish farming through the formation of the cooperatives $[6]$.

The concept of forming fishermen cooperative societies started late from 2012-2013 in Sikkim. At present state has Primary Fishermen Cooperatives Societies (PFCS) at the village level. The water bodies are gradually being brought under aquaculture with the formation of PFCS. The Department of Fisheries, Sikkim initiated the creation of fish farmers cooperatives based on the available number of farmers in clusters. They helped in the formation of 
cooperatives separately for carp and trout growers. The effectively functioning six PFCS are Upper Sribadam, Maneybong-Sopakha, Upper Rimbik, $20^{\text {th }}$ Chujachen, Mangshilla and Dalep. Under these cooperatives there are 102 members; 73 members are associated with trout farming while 29 members belong to carp farming. The main motives behind the formation of fishermen cooperative societies in Sikkim were to increase the level of fish production, generate employment opportunities and ensure a sustainable source of livelihood, raise adequate revenue for reinvestment and manage and conserve the fisheries resources on a sustainable basis.

Some of the research undertaken in the context of environmental sustainability and management of fishery resources are discussed below. Ajayi [7] estimated the MSY of the inshore fish and shrimp resources by using Schaefer's and exponential models for the periods 1965-1972. The study found that the MSY value for fish caught below $40 \mathrm{~m}$ and $50 \mathrm{~m}$ were 11684.09 and $13742.35 \mathrm{mt}$ for 50000 ha and 55000 ha fishing respectively. For shrimp, the estimated MSY was 2008.02 tonnes. It was also observed that the inshore fishery had the probability for further expansion but on the other hand, the shrimp resources have been fully exploited under the prevailing circumstances. Devaraj [8] used time-series data for the yr 197080 and 1971-82 to estimate the economically optimum catch and effort for the three major landing centers of Kerala i.e. Cochin, Shakthikulangara and Calicut by using cost, catch and price data. The authors have divided the total annual effort in boat $\mathrm{h}$ by the average trawling $\mathrm{h}$ per $\mathrm{d}$ i.e. $8 \mathrm{~h}$ to change the effort into boat per d. The estimated Maximum Economic Yield (MEY) was found to be 91323 tonnes of catch that comprises 44,931 tonnes of shrimp and 46392 tonnes of finfish. Similarly, the estimated MSY was observed to 96, 830 tonnes from the demersal stocks exploited by the trawlers and the biological optimum effort of 1503 trawlers per d for 215 fishing d a yr needed for the attainment of MSY. Aswathy et al. [9] analysed the bioeconomic conditions of commercially exploited marine fishes for assessing 
their sustainability in the context of existing management practices. MSY, MEY and open access levels of yield and effort were analysed using Gompertz-Fox growth model. The study concluded that the fishing effort exceeded the economically optimal levels and there is unnecessary wastage of money, manpower and fuel in the fishing industry. The study stressed the urgent need for capture fisheries management in the State which at present follows an openaccess fishery where regulations exist only in the form of seasonal closure in the monsoon season. The allocation of effort among fishing gears is as important as controlling effort concerning both sustainable yield and ecosystem management. Differences in age-specific vulnerability to the fishing method can modify the MSY that is obtainable from fish stock. Different gears or methods are more or less selective for the species targeted, and MSY is rarely, if ever, attainable simultaneously for all species. The different fishing methods capture different types of non-target species. Some methods will often be more profitable than others, and different user groups will prefer different methods. In many fisheries, it is unlikely that fishing can be limited to a single gear or method, so compromises among them will be required, Maunder [10]. Bhattacharya and Gupta [11] analyse the fish biodiversity of Digha fishery in Eastern India with empirical analysis. They studied the loss of biodiversity due to water pollution and the resultant impact on the fish harvested. These twin problems have been addressed simultaneously and modeled in an aggregate Gordon-Schaefer model for the Digha fishery. An economic biodiversity index and a variable for environmental quality have been included modifying the aggregate Gordon-Schaefer model. For estimating the parameters of the model, the Schnute method has been used. They focus on the dynamics of the profit maximising regime and explore the dynamic MEY and the net present value of profit by fishery is maximised. The small variation in discount rates and intrinsic growth rates have been done as a part of sensitivity analysis and their impact on optimal profit has been examined. This has been done under different biodiversity scenarios. They found that in the case of the Digha 
fishery, there exists a trade-off between economic biodiversity conservation and profit maximisation. Their study suggested that the government should framework the policy measures to minimise the level of conflict between them.

Fishery resources are renewable natural resources but natural stocks of fish have been decreasing day by day because of the rapid explosion of the human population and the resultant persistent and indiscriminate fish harvest $[12,13]$. Besides these, excessive extraction of fishes from water bodies for speedy and higher returns has resulted in disbalances in ecology and sustainability [14]. In this context, this paper attempts to evaluate the financial performances in terms of productivity and profitability, assess environmental sustainability and examine the trade-off between the financial performances and environmental management of the PFCS.

\section{Materials and methods}

The study is based on secondary data collected for six yr i.e. from the periods 2013-14 to 201819 for six PFCS located in four districts of Sikkim. The panel data technique was used to derive the results of the regression. The data was collected from the Department of Fisheries, Department of Cooperation, Government of Sikkim and the Primary Fishermen Cooperative Society. Three cooperatives from the West district and one each from East, South and North districts have been selected based on the existence of the number of cooperatives in each district. Of these 6 PFCS, 4 belong to trout farming and 2 carp farming. The number of ponds under each cooperative and membership is not the same; therefore, results have been analysed by $\mathrm{kg}$ per area of the pond.

\subsection{Evaluation of financial performances of PFCS}

The productivity and profitability analyses are the major ways of assessing or evaluating the feasibility or viability of an investment. Before making any investment in aquaculture, it is very crucial to assess whether the proposed investment yields positive returns or not [15]. The higher the profit, the greater is the scope for its reinvestment and the expansion of its 
functioning [14]. Therefore, to evaluate the investment in fish farming is worthwhile and feasible or not we have calculated productivity and profitability ratios [14,15]

$$
\begin{aligned}
& \text { Productivity }=\frac{\text { Total output of fish in monetary terms }}{\text { Total inputs in monetary terms }} \\
& \text { Profitability }=\frac{\text { profit }}{\text { cost }}
\end{aligned}
$$

If the profitability ratio is greater than 1 , investment in fish farming is profitable.

Profit $(\Pi)=$ Total revenue - Total cost

Total Revenue $(\mathrm{TR})=$ Total fish output $\mathrm{X}$ unit price of fish in ₹.

Total Cost $(\mathrm{TC})=$ sum of labor cost, input cost and other costs (maintenance cost, fishing cost etc.) in ₹

\subsection{Environmental sustainability and fisheries management}

Sustainable fishing and fish farming are the means to harvest fish at a sustainable rate, where the stock of fish does not decrease over time because of fish catch and fishing practices. The concept of sustainability is applicable in both capture and culture fisheries for effective regeneration of their stock and continuous cycle of growth of fish and harvest. Water bodies like ponds, lakes, tanks, etc. are governed on the basis of culture-based fisheries or various other forms of enhancement which are intermediate to both culture and capture fishery. Such kind of management can be taken up in more eco-friendly ways by maintaining the stock of fish [14]. In this context, the study analyses whether the PFCS's annual fish catch lies below the MSY or falls in the borderline case, or surpasses it becomes very crucial. The environmental sustainability of the different cooperative societies is examined by using the concept of MSY through the application of the Gordon-Schaefer Model $[7,12,14]$. According to Schaefer's model, catch per unit of effort (Y/E) is assumed to be proportional to the density of fish. The density of fish is supposed to be proportional to stock whereby the harvest level is written as $\mathrm{Y}=\mathrm{qEX}$, where $\mathrm{q}$ represents the catchability coefficient. This is known as the Gordon-Schaefer production function. The effort index is defined as the fishing labour cost (rearing and 
harvesting) per fishermen as a percentage of other inputs cost. Other input costs include the cost of seeds and feeds, maintaining and repairing cost and miscellaneous cost.

The effort index is calculated as follows:

$$
\text { Effort Index }=\frac{\text { Labour cost per fishermen }}{\text { Other input costs }} \mathrm{X} 100
$$

The growth of fish population X can be expressed mathematically by the well-known logistic equation

$$
=\frac{\mathrm{dX}}{\mathrm{dt}}=\mathrm{rX}\left(1-\frac{\mathrm{X}}{\mathrm{K}}\right)
$$

Subject to harvest at rate $\mathrm{Y}$, we rewrite the net rate of growth as

$$
\dot{\mathrm{X}}=\frac{\mathrm{dX}}{\mathrm{dt}}=\mathrm{rX}\left(1-\frac{\mathrm{X}}{\mathrm{K}}\right)-\mathrm{Y}
$$

However, using the production function we can rewrite the equation as

$$
\dot{X}=\operatorname{rX}\left(1-\frac{X}{K}\right)-q E X
$$

Here $\mathrm{r}=$ intrinsic growth rate of fish stock $(1 / \mathrm{yr})$ and $q E=\frac{Y}{E}$ implies catch standardized for fish stock or catch per unit of biomass.

Here the criterion of sustainability requires the equality $\frac{d X}{d t}=Y$ which implies

$$
\mathrm{r} \dot{\mathrm{X}}\left(1-\frac{\mathrm{X}}{\mathrm{K}}\right)=\mathrm{qEX} \text { whereby we get, } \mathrm{X}=\mathrm{K}\left(1-\frac{\mathrm{qE}}{\mathrm{r}}\right)
$$

After some mathematical manipulation, we get

$$
\begin{gathered}
\mathrm{Y}=\mathrm{aE}-\mathrm{bE} \mathrm{E}^{2} \\
Y=E(a-b E)
\end{gathered}
$$


It implies that

$$
\begin{aligned}
\left(\frac{Y}{E}\right) & =a-b E \text {--------------- Eq. (1) } \\
Y & =a E-b E^{2} \text {----------------Eq. (2) }
\end{aligned}
$$

The optimum effort level and MSY corresponding to this equation can be found by using the first-order condition as

$$
\begin{gathered}
\frac{d y}{d E}=1-2 b E=0 \\
\hat{E}=\frac{\hat{a}}{2 \hat{b}}-\cdots
\end{gathered}
$$

Substituting equation 3 into equation 2, we get

$$
\begin{gathered}
Y=a\left(\frac{a}{2 b}\right)-b\left(\frac{a}{2 b}\right)^{2} \\
\text { or } \frac{a^{2}}{2 b}-\frac{a^{2}}{4 b} \\
\text { or } \frac{2 a^{2}-a^{2}}{4 b} \\
\hat{Y}_{\text {MSY }}=\frac{\hat{a}^{2}}{4 \hat{b}}
\end{gathered}
$$

$$
\text { Hence, } \widehat{\mathrm{E}}=\frac{\hat{\mathrm{a}}}{2 \widehat{\mathrm{b}}} \text { and MSY }=\frac{\hat{\mathrm{a}}^{2}}{4 \hat{b}}
$$

For incorporating species-specific effect, we carried out regression analysis with a categorical dummy by using Least Square Dummy Variable (LSDV) model. For this purpose, following modified Gordon-Schaefer model has been used.

$$
\left(\frac{Y}{E}\right)_{i t}=a_{1}-b E_{i t}+a_{2} D_{i}+\mu_{i t}-\ldots-\ldots \text { - Eq. (5) }
$$

where the subscript $\mathrm{i}=1, \ldots, \mathrm{N}$ indicates the PFCS and subscript $\mathrm{t}=1, \ldots, \mathrm{T}$ indicates the time (yr). In the regression model, a and b are the constants, the dependent variable $\left(\frac{Y}{E}\right)$ is the yield 
per unit of effort, E represents effort index, $\mathrm{D}_{\mathrm{i}}($ dummy variable $)=1$ if the fish species belong to the carp family, 0 otherwise, $u_{i t}$ represents the error term. The coefficients $a_{1}, a_{2}$ and $b$ are estimated by applying equation (3) using the least-squares technique.

\section{Results and discussion}

Tables 1 and 2 illustrate the results of the financial performances of trout and carp growers' PFCS from the periods 2013-14 to 2018-19.

In the case of Sribadam, productivity and profitability were showing a more or less growing trend except for a slight decline in 2015-16 because in this period the cooperative had to bear extra costs for the maintenance. During the period 2016-17, profit was declined due to a decrease in fish and an increase in input costs. However, the overall performances of the cooperative indicate an improvement in all indicators along with positive returns from the investment.

In Maneybong-Sopakha, production has increased over the periods but slightly declined in 2015-16 and 2018-19 which was because of the less availability of the fish feeds from the Government. But there were improvements in productivity and profitability because the members managed their ponds effectively. Conversely, in the period 2017-18, productivity and profitability have declined as a consequence of the rise in labour wages and input costs. 
Table 1 Evaluation of financial performances of trout growers' PFCS

\begin{tabular}{|c|c|c|c|c|c|}
\hline $\begin{array}{l}\text { Name of } \\
\text { PFCS }\end{array}$ & Year & Production & Productivity & Profit & Profitability \\
\hline Upper & 2013-14 & 175 & 4.883 & 69583.33 & 3.883 \\
\hline \multirow[t]{5}{*}{ Sribadam } & 2014-15 & 250 & 3.546 & 89758.33 & 2.546 \\
\hline & $2015-16$ & 195 & 3.052 & 91775.69 & 2.052 \\
\hline & 2016-17 & 175 & 3.288 & 85245.88 & 2.288 \\
\hline & $2017-18$ & 206 & 4.189 & 125660.21 & 3.189 \\
\hline & 2018-19 & 254 & 4.063 & 153199 & 3.063 \\
\hline Maneybong- & 2013-14 & 140 & 4.560 & 54651.99 & 3.560 \\
\hline \multirow[t]{5}{*}{ Sopakha } & 2014-15 & 219 & 3.408 & 77394.37 & 2.408 \\
\hline & $2015-16$ & 165 & 3.684 & 72130.84 & 2.684 \\
\hline & 2016-17 & 200 & 4.462 & 108625.35 & 3.462 \\
\hline & $2017-18$ & 220 & 4.009 & 132104.618 & 3.009 \\
\hline & 2018-19 & 192 & 4.235 & 117524.38 & 3.235 \\
\hline Upper & 2013-14 & 145 & 3.128 & 49325 & 2.128 \\
\hline \multirow{5}{*}{ Rimbik- } & 2014-15 & 47.5 & 0.772 & -7000 & -0.227 \\
\hline & $2015-16$ & 83.333 & 0.942 & -2520.83 & -0.057 \\
\hline & 2016-17 & 150 & 2.769 & 47916.66 & 1.769 \\
\hline & 2017-18 & 146.666 & 2.476 & 52466.67 & 1.476 \\
\hline & 2018-19 & 100 & 2.258 & 54500 & 1.258 \\
\hline $20^{\text {th }}$ & 2013-14 & 125 & 2.463 & 42000 & 1.463 \\
\hline \multirow[t]{5}{*}{ Chujachen } & 2014-15 & 132 & 2.587 & 44242 & 1.587 \\
\hline & $2015-16$ & 120.5 & 2.689 & 56369.75 & 1.689 \\
\hline & 2016-17 & 84.2 & 2.567 & 39885 & 1.567 \\
\hline & $2017-18$ & 126 & 2.682 & 67725 & 1.682 \\
\hline & 2018-19 & 158.88 & 2.970 & 104540 & 1.970 \\
\hline
\end{tabular}

Source: Author's estimation

Unfortunately, productivity and profitability had declined significantly in Upper Rimbik during the periods 2014-15 and 2015-16 due to landslides. Profitability became negative and the rate of productivity was also less than 1 during those periods. The Government refinanced and provided economic and technical support for its quick resuscitation. 
In $20^{\text {th }}$ Chujachen, production was lowest in the yr 2016-17 and declined for the periods 2015-16 and 2016-17 due to some biological causes. However, there was less variability in productivity and profitability of the society over the periods due to the hike in prices.

Table 2 Evaluation of the financial performance of carp growers' PFCS

\begin{tabular}{lccccc}
\hline $\begin{array}{l}\text { Name of } \\
\text { PFCS }\end{array}$ & Year & Production & Productivity & Profit & Profitability \\
\hline Mangshilla & $2013-14$ & 120 & 5.419 & 19571.428 & 4.419 \\
& $2014-15$ & 128 & 7.314 & 22100 & 6.314 \\
& $2015-16$ & 110.33 & 6.572 & 23386.071 & 5.572 \\
& $2016-17$ & 93.2 & 4.807 & 18453.333 & 3.807 \\
& $2017-18$ & 102.6 & 5.463 & 25146.666 & 4.463 \\
& $2018-19$ & 120.024 & 5.374 & 29307.2 & 4.374 \\
& $2013-14$ & 90 & 5.688 & 11126.66 & 4.688 \\
& $2014-15$ & 63 & 3.705 & 9200 & 2.705 \\
& $2015-16$ & 79.5 & 3.816 & 11733.333 & 2.816 \\
& $2016-17$ & 93 & 3.838 & 13754 & 2.838 \\
& $2017-18$ & 63.2 & 3.019 & 10566.666 & 2.019 \\
& $2018-19$ & 76.8 & 3.217 & 13233.333 & 2.217 \\
\hline
\end{tabular}

Source: Author's estimation

In the case of Mangshilla, production was recorded lowest during the yr 2016-17 and 2017-18 due to the non-availability of required fish seeds on time. This cooperative had the highest level of productivity and profitability among all others because the cost of inputs like the price of seeds and feeds was less for carp farming compared to trout farming.

Similarly, for Dalep, there was less variation in profitability and productivity ratios. This cooperative had the lowest level of fish production compared to others because it has fewer fish farmers and ponds with water scarcity.

Table 3 Result of pooled regression and LSDV model 


\begin{tabular}{lcccc}
\hline \multirow{2}{*}{ Variables } & \multicolumn{2}{c}{$\begin{array}{c}\text { Restricted model (Pooled } \\
\text { regression) }\end{array}$} & \multicolumn{2}{c}{$\begin{array}{c}\text { Unrestricted model } \\
\text { (LSDV model) }\end{array}$} \\
\cline { 2 - 5 } & Coefficient & t-value & Coefficient & t-value \\
\hline effort & $-19.077 * *$ & -2.24 & $-16.587 * *$ & -2.14 \\
$\mathrm{D}_{\mathrm{i}}$ & & & $-29.863 * * *$ & -2.91 \\
constant & $102.933 * * *$ & 4.43 & $116.839 * * *$ & 5.42 \\
$\mathrm{~F}$-statistic & $5.04 * * *$ & & $7.31 * * *$ & \\
$\mathrm{R}^{2}$ & 0.129 & & 0.307 & \\
\hline
\end{tabular}

Source: Author's estimation.

Note: $* * *, * *$ and $*$ indicates the significance levels at $1 \%, 5 \%$ and $10 \%$ respectively.

In the restricted model as shown in Table 3, the effort is significant at 5\% level with its expected sign. The negative value of $\hat{b}$ implies that for a unit increase in the effort level the estimated average yield per unit of effort falls by 19.07 units. The F statistic is significant at $5 \%$ level and the estimated equation is found to be a good fit.

Also, in the unrestricted model (Table 3), the effort is significant with its expected sign. More interestingly dummy variable is also statistically significant, which indicates that the species-specific effect exists on the level of effort as well as on the harvest level. This is quite natural because, firstly, trout is a very high-value nutritional species. Secondly, trout culture has been promoted extensively by the government. Thirdly, fishermen prefer trout culture compared to carp due to high profitability. The estimated mean yield per unit of the effort of the trout fish is $116.84 \mathrm{~kg}$ while that of the carp fish is lower by $29.86 \mathrm{~kg}$, i.e. $87 \mathrm{~kg}$ (given in Table 4). The value of $\mathrm{R}^{2}$ and $\mathrm{F}$ indicates that the model is rather a good fit.

Table 4 Results of estimation of the yield-effort equation for PFCS

\begin{tabular}{lcccccc}
\hline PFCS & $\begin{array}{c}\text { Constant } \\
\left(\mathbf{a} 1, \mathbf{a}_{2}\right)\end{array}$ & $\begin{array}{c}\text { Coefficient } \\
(\mathbf{b})\end{array}$ & $\mathbf{R}^{2}$ & $\mathbf{F}$ & MSY & $\begin{array}{c}\text { Average } \\
\text { Yield }\end{array}$ \\
\hline \multirow{2}{*}{ Trout } & $116^{* * * *}$ & $-16.587 * *$ & 0.30 & $7.31 * * *$ & 202.814 & 158.80 \\
& & & & & & \\
& $(5.42)$ & $(-2.41)$ & & & & \\
Carp & $87 * * *$ & $-16.587 * *$ & 0.30 & $7.31 * * *$ & 114.069 & 91.95 \\
& $(-2.91)$ & $(-2.41)$ & & & & \\
\hline
\end{tabular}

Source: Author's estimation

Note: $* * *, * *$ and $*$ indicate the significance levels at $1 \%, 5 \%$ and $10 \%$ respectively and figures within the brackets represent the t- statistics 
Based on the result obtained from the LSDV model (Table 3), MSY for trout and carp growers PFSC has been calculated separately (Table 4). The value of MSY is equal to $202.814 \mathrm{~kg}$ for trout and $114.069 \mathrm{~kg}$ for carp.

Tables 5 and 6 illustrate the yr-wise variation of actual yield from MSY and their implications for trout and carp growers PFCS. In the case of Sribadam, the actual yield is higher than the MSY and the ratio of actual yield to MSY exceeds 1 for the periods 2014-15, 201718 and 2018-19 and the remaining yr it is close to 1 indicating that there is a greater threat of actual yield surpassing the MSY. A harvest level greater than or close to MSY indicates that there is less concern for environmental sustainability, future growth of the fish resource and stock generation. The mean actual yield is 209.22 and the mean absolute deviation of the ratio from 1 is 0.1358 indicating that on average $86.42 \%$ of MSY is harvested keeping only 13.58 $\%$ for a stock generation.

Similarly, for Maneybong- Sopakha, the actual yield is higher than the MSY and the ratio of actual yield to MSY exceeds 1 for the yr 2014-15 and 2017-18 and is very close to 1 for the remaining yr. Harvest levels exceeding the MSY indicate a disregard for environmental sustainability and complete unconcern regarding the future stock of resources. The mean actual yield is 189.39 with the mean absolute deviation of the ratio from 1 is 0.1211 , indicating that on an average $87.89 \%$ is harvested leaving relatively smaller stocks for future generations of about $12.11 \%$.

Considering the case of Upper Rimbik, their actual yield is lower than the MSY in all the yr and the ratio of actual yield to MSY is also less as compared to the previous two societies. The mean actual yield is rather low at 112.08 and the mean absolute deviation of the ratio from 1 is 0.4474 indicating that on an average $55.26 \%$ is harvested leaving $44.74 \%$ for a future stock generation.

Table 5 Comparative results for actual yield and MSY for trout growers' PFCS 


\begin{tabular}{|c|c|c|c|c|c|}
\hline Name of PFCS & Year & $\begin{array}{l}\text { Actual } \\
\text { Yield }\end{array}$ & $\begin{array}{l}\text { MSY } \\
\left(\mathbf{Y}_{\mathbf{m}}\right)\end{array}$ & $\begin{array}{l}\text { Ratio of } \\
Y_{a} \text { to } Y_{m}\end{array}$ & $\left|\mathbf{Y}_{\mathrm{a}} / \mathbf{Y}_{\mathrm{m}-1} \mathbf{1}\right|$ \\
\hline \multirow[t]{6}{*}{ Upper Sribadam } & $2013-14$ & 175 & 202.814 & 0.862 & 0.137 \\
\hline & 2014-15 & 250 & 202.814 & 1.232 & 0.232 \\
\hline & $2015-16$ & 195 & 202.814 & 0.961 & 0.038 \\
\hline & 2016-17 & 175 & 202.814 & 0.862 & 0.137 \\
\hline & 2017-18 & 206.315 & 202.814 & 1.017 & 0.017 \\
\hline & 2018-19 & 254 & 202.814 & 1.252 & 0.252 \\
\hline \multirow[t]{6}{*}{ Maneybong- Sopaka } & 2013-14 & 140 & 202.814 & 0.690 & 0.309 \\
\hline & $2014-15$ & 219.047 & 202.814 & 1.080 & 0.080 \\
\hline & $2015-16$ & 165 & 202.814 & 0.813 & 0.186 \\
\hline & 2016-17 & 200 & 202.814 & 0.986 & 0.013 \\
\hline & 2017-18 & 220 & 202.814 & 1.084 & 0.084 \\
\hline & 2018-19 & 192.307 & 202.814 & 0.948 & 0.051 \\
\hline \multirow[t]{6}{*}{ Upper Rimbik- } & 2013-14 & 145 & 202.814 & 0.714 & 0.285 \\
\hline & $2014-15$ & 47.5 & 202.814 & 0.234 & 0.765 \\
\hline & $2015-16$ & 83.333 & 202.814 & 0.410 & 0.589 \\
\hline & 2016-17 & 150 & 202.814 & 0.739 & 0.260 \\
\hline & $2017-18$ & 146.666 & 202.814 & 0.723 & 0.276 \\
\hline & 2018-19 & 100 & 202.814 & 0.493 & 0.506 \\
\hline \multirow[t]{6}{*}{$20^{\text {th }}$ Chujachen } & $2013-14$ & 125 & 202.814 & 0.616 & 0.383 \\
\hline & 2014-15 & 132.142 & 202.814 & 0.651 & 0.348 \\
\hline & $2015-16$ & 120.714 & 202.814 & 0.595 & 0.404 \\
\hline & 2016-17 & 84.285 & 202.814 & 0.415 & 0.584 \\
\hline & $2017-18$ & 126 & 202.814 & 0.621 & 0.378 \\
\hline & 2018-19 & 158.888 & 202.814 & 0.783 & 0.216 \\
\hline
\end{tabular}

Source: Author's estimation

$20^{\text {th }}$ Chujachen, their actual yield is lower than MSY and the ratio of actual yield to MSY is moderate for all the yr. The mean actual yield is 124.5052 and the mean absolute deviation of the ratio from 1 is 0.3308 , indicating that on average $66.92 \%$ of MSY is realised keeping $33.08 \%$ for a stock generation.

Table 6 Comparative results for actual yield and MSYfor carp growers' PFCS 


\begin{tabular}{lccccc}
\hline Name of PFCS & Year & $\begin{array}{c}\text { Actual } \\
\text { Yield }\end{array}$ & $\begin{array}{c}\text { MSY } \\
\left(\mathbf{Y}_{\mathbf{m}}\right)\end{array}$ & $\begin{array}{c}\text { Ratio of } \\
\mathbf{Y}_{\mathbf{a}} \text { to } \mathbf{Y}_{\mathbf{m}}\end{array}$ & $\left|\mathbf{Y}_{\mathbf{a}} / \mathbf{Y}_{\mathbf{m}} \mathbf{- 1}\right|$ \\
\hline Mangshilla & $2013-14$ & 120 & 114.069 & 1.051 & 0.051 \\
& $2014-15$ & 128.88 & 114.069 & 1.129 & 0.129 \\
& $2015-16$ & 110.33 & 114.069 & 0.967 & 0.032 \\
& $2016-17$ & 93.22 & 114.069 & 0.817 & 0.182 \\
& $2017-18$ & 85.5 & 114.069 & 0.749 & 0.250 \\
& $2018-19$ & 100.02 & 114.069 & 0.876 & 0.123 \\
& $2013-14$ & 90 & 114.069 & 0.788 & 0.211 \\
& $2014-15$ & 63 & 114.069 & 0.552 & 0.447 \\
& $2015-16$ & 79.5 & 114.069 & 0.696 & 0.303 \\
& $2016-17$ & 93 & 114.069 & 0.815 & 0.184 \\
& $2017-18$ & 63.2 & 114.069 & 0.554 & 0.445 \\
$2018-19$ & 76.8 & 114.069 & 0.673 & 0.326 \\
\hline
\end{tabular}

Source: Author's estimation

Considering Mangshilla, their actual yield is higher than the MSY for the yr 2013-14 and 2014-15 and also exceeds the value 1 in the ratio of actual yield to MSY while for the remaining yr, it is close to 1 . The mean actual yield is rather high at a value of 106.325 and the mean absolute deviation of the ratio from 1 is 0.1285 signifying on the average $87.15 \%$ of MSY is harvested keeping a relatively smaller portion of about $12.85 \%$ for a further stock generation.

Lastly, for Dalep, their average yield of fish is less than the MSY level in all the yr while the ratio of actual yield to MSY is higher for the years 2013-14 and 2016-17; it is moderate in the remaining yr. The mean actual yield is 77.58 and the mean absolute deviation of the ratio from 1 being 0.3198 revealing that on average $68.11 \%$ of MSY is being reaped leaving $31.98 \%$ for a future stock generation. From the above discussion, it is clear that the PFCS like Rimbik, $20^{\text {th }}$ Chujachen and Dalep are much more concerned with stock generation and maintaining sustainability as compared to the other three cooperatives.

\section{Conclusions}


It can be concluded from the above results that PFCS such as Upper Sribadam, Manebong Sopakha and Mangshilla had been obtained higher financial achievements in fish farming; at the same time, there is a threat of sustainability because in some of the yr the actual yield surpasses the MSY. These cooperatives have paid more attention to profit generations and relatively less to environmental sustainability. On the other hand, PFCS like Upper Rimbik, Chujachen and Dalep have not been able to keep their financial management up to the mark but then they had given more concern to sustainability and maintained a relatively substantial amount for the future generations as compared to the former three cooperatives. Their actual yield is less than the MSY in all the periods. More financial gains like more productivity and profitability mean more extraction of existing resources implying less scope of regeneration for the future which indicates a trade-off between the financial management and environmental sustainability of resources. It is to be noted that although sustainability is maintained by the cooperatives, there is a lack of stability in the sustainability factor as is evident from the observed fluctuations in the considered ratio of actual yield to MSY. Nevertheless, positive returns from investment in fisheries are very essential for proper functioning and reinvestment for the succeeding periods but coldwater fish species in the Himalayas have been greatly shrunk due to manmade activities and natural factors resulting in the degradation of ecology. Hence, it has become very crucial to conserve, manage and utilize resources on a sustainable basis.

\section{Declarations}

\section{Availability of data and materials}

All data generated or analysed during this study are included in this article. The raw data are available from the corresponding author upon reasonable request.

\section{Competing interests}

The authors (KBC and RK) declared they have no competing interests. 


\section{Funding}

The author(s) do not receive any financial support for the research, authorships/or publication of this article.

\section{Authors' contribution}

KBC prepared and drafted the manuscripts. RK critically reviewed and edited the final manuscript. Both the authors read and approved the final manuscript.

\section{Acknowledgements}

We would like to express our hearty gratitude to Prof. Jeta Sankrityayana, Department of Economics, Sikkim University; Prof. Soumyendra Kishore Datta, University of Burdwan; Dr. Indraneel Mandel, Assistant Professor, Institute of Technology and Science, Ghaziabad: Dr. Srikanta Kundu, Assistant Professor, Centre for Development Studies, Kerala for inspiring and guiding us during this manuscript writing.

\section{References}

1. Singh AK. Advances in Indian coldwater fisheries and aquaculture. Journal of Fisheries Sciences. com. 2015 Jul 1;9(3):48.

2. Jhingran VG, Sehgal KL. Coldwater fisheries of India. Coldwater fisheries of India. 1978.

3. Sehgal KL. Coldwater fish and fisheries in the Indian Himalayas: rivers and streams. Fish and fisheries at higher altitudes: Asia. Food and Agriculture Organization of the United Nations Technical Paper. 1999; 385:41-63.

4. Munilkumar S, Nandeesha MC. Aquaculture practices in Northeast India: Current status and future directions. Fish physiology and biochemistry. 2007 Dec 1;33(4):399412. 
5. Mahanta PC, Singh SD, Sarma D. Coldwater Fisheries Development in India with Special Reference to North East India.

6. Department of Animal Husbandry, Livestock, Fisheries and Veterinary Services, Government of Sikkim, Annual Report 2017-2018. http://www.sikkimahvs.gov.in/fisheries_development.html.

7. Ajayi TO. The maximum sustainable yields of the inshore fish and shrimp resources of the Nigerian continental shelf. Journal of Fish Biology. 1982 May;20(5):571-7.

8. Devaraj, M. and Smita, P., 1988. Economic performance of mechanised trawlers in the State of Kerala, India. Fisheries research, 6(3), pp.271-286.

9. Aswanthy N, Shanmugam TR, Ashok KR, Sathiadhas R. A bioeconomic analysis of sustainability of marine fish production in Kerala. Journal of the Indian Fisheries Association. 2009; 36:1-8.

10. Maunder MN. The relationship between fishing methods, fisheries management and the estimation of maximum sustainable yield. Fish and Fisheries. 2002 Dec;3(4):25160. https://doi.org/10.1046/j.1467-2979.2002.00089.x.

11. Gupta AC, Bhattacharya RN. Fish biodiversity of Digha fishery in eastern India: an empirical analysis. Ecology and Human Well-being, New Delhi: Sage Publications. 2007 Jul 3:69-92.

12. Petr T, Swar DB, Swar SB, editors. Cold water fisheries in the trans-Himalayan countries. Food \& Agriculture Org.; 2002.

13. Narayanakumar R. Maximum economic yield and its importance in fisheries management. 2017

14. Datta SK, Ghosh AR, Kundu R. Tradeoff between Economic and Environmental Management of Two Fish Production Units in Burdwan District of West Bengal. Environment and Ecology. 2006 Mar;24(1):237-41. 
15. Olasunkanmi JB. Economic analysis of fish farming in Osun state, South-Western Nigeria. 2012. 